\title{
Reframing hunting, gathering, tool-making and art, as expressions of evolution of consciousness as depicted in Jean Gebser's 'the ever-present origin'
}

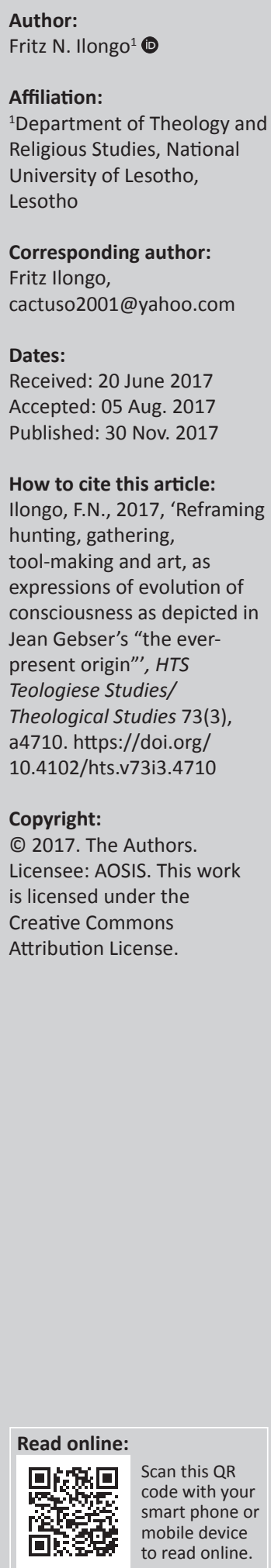

This article explores the evolution of consciousness as directly correlated to hunting, gathering, tool-making and art. The methodology is qualitative theoretical analyses, articulated around Jean Gebser's seminal work, The Ever-Present Origin. Hunting and gathering are expressions of a magical, unitary, 'self-dissolving' consciousness. Tool-making on the other hand is depicted as evolving from a mythical consciousness of duality, polarity, symbolism and a state of being qualified by 'crystallisation of the I'. Lastly, art is a function of a consciousness of 'selftranscendence', 'I and I', idealisation and a transpersonal state of being. The article concludes by positing that hunting, gathering, tool-making and art can be reframed as 'forms of the movement of consciousness'.

\section{Opening reflections}

\section{Defining and reframing key concepts}

\section{Hunting and gathering}

According to Dictionary.com (2017), hunting and gathering refer to the action of relying primarily or exclusively on hunting wild animals, fishing and gathering wild fruits, berries, nuts and vegetables to support one's diet, Until hunter- began to domesticate plants and animals about 10000 years ago, all human societies were hunter-gatherers.

Hunting and gathering are also defined as follows:

1. Of a society, lifestyle, surviving by hunting animals and gathering plants for subsistence.

2. Hunting-gathering is associated with uncivilised people, that is, those lacking culture or sophistication. Civilised means having a highly developed society and culture. Civilisation is generally defined as people who have attained a triple combination of industrial capability, technological sophistication and economic productivity.

\section{Tool-making}

The history of technology is the history of the invention of tools and techniques ranging from as simple as language and stone tools to the complex genetic engineering and information technology that has emerged since the 1980s. New knowledge has enabled people to create new things, and conversely, many scientific endeavours are made possible by technologies that assist humans in travelling to places they could not previously reach and by scientific instruments by which we study nature in more detail than our natural senses allow.

\section{Art and the evolution of consciousness}

The eye sees only what the mind is prepared to comprehend. (Robertson Davies as quoted in The White Bedouin [2007] by George Potter, p. 241)

The idea that consciousness, or experience, has evolved and may continue to evolve through time and history has been explored in one way or another by many philosophers and pioneers of the inner life, but is seen nowhere more clearly than in the history of art. No one understood this better than the poet and cultural historian Jean Gebser, who contributed perhaps more than any other scholar to understanding the history of human consciousness.

Gebser's explorations of art and history begin with a sudden recognition that art at the fin de siècle represented a new kind of consciousness, a new way of seeing and experiencing reality. With this in mind, he searched backward through history to uncover a whole series of 'structures of 
consciousness' that had emerged in order, starting with the earliest humans. Each structure represented a major way of understanding the world; through archaic, magic, myth, rational thought or in an integral way.

\section{Reframing hunting, gathering, tool-making and art}

Hunting, gathering, tool-making and art are forms of human activities (tertiary level), but what are the movements of consciousness or dis-consciousness (secondary level), and form of the movement of the form (primary level) that accompany these 'activities' and what other forms do they point to?

The form of hunting, gathering, tool-making and art may appear 'primitive or civilised', but one has to consider their underlying movements of energy (feeling, thought and imagination), and the still more central intention or form of the movement of the form. In other words, the form is the form, but 'its fruits or outcomes' are more important than the 'appearance of the form'. And the fruits of outcomes are a function of 'consciousness' or 'dis-consciousness' as the case may be. The intention therefore determines the movement of the form, form of the movement and most importantly the 'use' to which will be put the form. We could reframe hunting, gathering, tool-making and art by asking ourselves the following questions:

1. Is humankind not still a hunter-gatherer in the 21st century despite all the technological developments of the moment?

2. Does technological development imply an equal and convergent development of consciousness?

3. Can we not also intimate that the hunter-gatherer of 10000 years ago had a higher consciousness, lower physical technology, but may have had a higher mind technology?

4. Can we not presume that today mankind has a higher technology, lower consciousness and even lower mind technology?

5. Does it mean a people can be 'civilised' and at the same time 'barely existing' because though they are technologically advanced, they lack an equal or higher level of consciousness development which transcends their level of technical development?

6. Are currently technologically advanced cultures 'consciously underdeveloped' and therefore 'only surviving or barely existing' far below their consciousness threshold, which is a source of optimal, holistic living?

7. Is the quality of existence not determined by the quantity of substance and energy directed towards consciousness development, and not a function of the quantity of substance and energy directed towards survival, or physical development and sense gratification at the expense of awareness?

8. Which serves the other, intelligence or consciousness?

9. Does information without the capability of meaningmaking or conscious awareness, not make the former meaningless?

\section{Consciousness}

Jean Gebser described his theory of consciousness in his masterpiece The Ever Present Origin (1985). He was one of the greatest contributors to the study of the evolution of consciousness, and he believed that its changes could be seen throughout history in art (Combs 2014). Gebser (1985) saw consciousness as a wakeful presence that was not identical with intelligence, and he outlined five mutations, or structures of this consciousness. According to Georg Feuerstein (1987), Gebser did not see consciousness as solely a witnessing function, but as an active and directive force, implying that consciousness is not only evolving in response to a relationship with phenomena, but that it is independently an initiator of the mutations. The representation of this new relationship with the world, and way of understanding, is illustrated in Gebser's five structures of consciousness: archaic, magical, mythical, mental, and integral (Combs 2014).

\section{Gebser's archaic structure of pre- consciousness \\ Archaic structure}

Gebser (1985) used the term archaic to describe the structure he said was originally identical to origin. There is no perspective, no sense of otherness, and the distinction between object and subject does not exist; there is no differentiation between self and nature, or between self and universe (Mohrhoff 2008). This initial structure, as Gebser (1985) stated, is only a structure in a sense for us to conceptualise it; there is nothing defining or separating parts of it from each other. He saw it as a 'structure emanating from that perfect identity existing "before" (or behind) all oneness or unity which it initially represented' (p. 43). In relation to our contemporary associations with consciousness, it could be called 'pre-consciousness' (Mohrhoff 2008). The apprehension of individual self is at this stage dormant, and all that exists is complete unity, 'a time of complete nondifferentiation of man and universe' (Gebser 1985:43).

For this researcher, consciousness implies the following states of awareness:

1. Consciousness is the realisation, affirmation and manifestation of the integral continuity of Being (unity, continuity, and infinity of substance, energy, light and power), Knowing (realisation of the unity, continuity and infinity of substance, energy, light and power) and Doing (transformation of integral, continuous, infinite substance, energy, light, and power).

2. Consciousness for him can be more likened to 'Awareness', in that the latter realises, affirms and manifests 'only the unity, continuity and infinity' of Being, knowing and Doing as defined. Furthermore, consciousness or 'awareness' for the researcher also 'actively dissolves' the perception, evocation and crystallisation of non-integral discontinuity of non-being (separation, discontinuity, limitation of substance, energy, light and power). In other words, 'consciousness' does not 'perceive' separation, 
discontinuity and limitation of substance, energy, light and power, in which case the latter 'become dissolved in its presence or essence'.

3. Consciousness implies trans-personalisation, or transcendence of 'perception of dualities', because of its fundamental characteristic of 'integral continuity'.

4. There can only be evolution in the 'presence of consciousness'.

5. Consciousness determines the 'direction-orientationeffect of the forms and outcomes' of hunting, gathering, tool-making and art. The forms and quality of the outcomes of hunting, gathering, tool-making and art directed by consciousness have the following attributes:

a. Dissolution of separation, discontinuity and limitation of substance, energy, light and power.

b. Crystallisation of unity, continuity and infinity of substance, energy, light and power.

c. Reconciliation of substance, energy, light and power.

d. Liberation of substance, energy, light and power.

e. Regenerating, recreating of substance, energy, light and power.

6. Consciousness can be described as the ability to have awareness or realisation of the unity of perceived information and to retain the essence of the latter as creative power for positive interaction with and transformation of self and the environment.

Consciousness is therefore an attribute of the soul, that is, consciousness is a 'soul sense'. There can therefore be soulful or conscious-intelligent hunting, gathering, tool-making and art.

\section{Model of consciousness evolving through four prisms of hunting, gathering, tool-making and art}

The model of consciousness that the researcher is proposing evolves through four prisms, which are, respectively, labelled the enabling, neutral, sustaining and reinforcing dimensions as seen in Figure 1. Hunting, gathering, toolmaking and art are, respectively, associated to the aforementioned prisms as expressions and experiences of corresponding stages of evolution of consciousness, that is, realisation of the unity, continuity and infinity of being, knowing and doing.

\section{The enabling dimension}

\section{Hunting}

What is humankind hunting for?

The primary, initiating point of consciousness as seen in Figure 1 is the 'enabling dimension', which is characterised by hunting for unity and integration by resisting fragmentation. The enabling dimension represents intention or form of the movement of the form of consciousness. The enabling dimension also stands for 'will' or the intention to resist fragmentation and strive for unity and integration.

\section{Evolution of consciousness through hunting \\ Hunting and Gebser's magical structure of consciousness}

\section{Resisting fragmentation}

This structure marks a beginning in the growth of selfconsciousness. However, there is still a strong association of self with nature. Identity is in terms of collective, or tribe, while space and time are present in each moment (Combs 2014). To describe the sense of space and identity, Gebser (1985) used the point. He said the point is on the one hand the representation of the birth of a centring in mankind, which later leads to ego and on the other hand an expression of the spacelessness and timelessness of the one-dimensional world. There is no interior experience, only an outer awareness and mankind's consciousness, which is at once separate and part of their environment. It does not lie within them but is of the world (Gebser 1985). From this standpoint, mankind assimilates this consciousness as a confrontation, and they learn to be aware of, and a part of the forces of nature. Within this structure, mankind's desire to have nature, as opposed to being part of it, has germinated, and this need develops their conscious will (Gebser 1985).

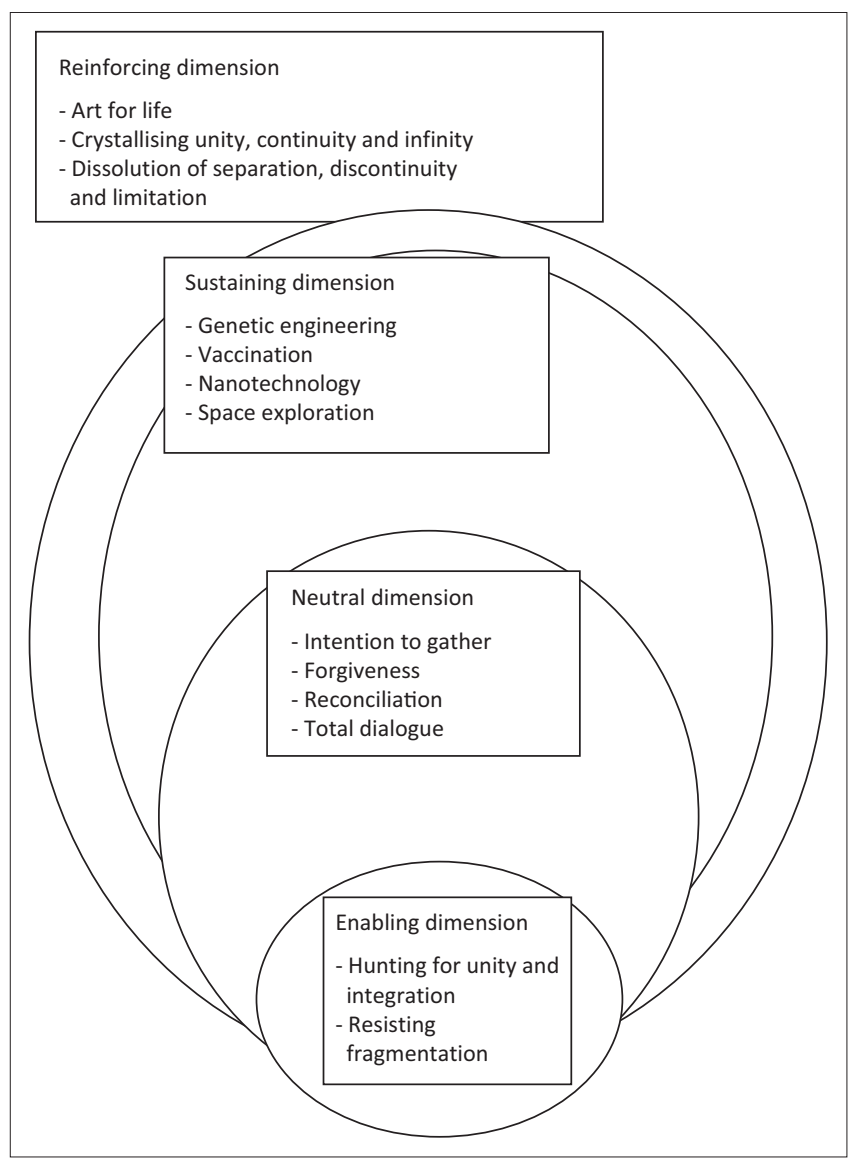

FIGURE 1: Model of consciousness evolving through four prisms of hunting, gathering, tool-making and art. 


\section{Hunting and consciousness of unity, continuity and infinity of being, knowing and action}

\section{A hunting scene}

In his book Unknown Africa (1933), Leo Frobenius describes the following rite, which he observed in the Congo jungle:

$[M]$ embers of the hunting tribe of Pygmies (three men and a woman) drew a picture of an antelope in the sand before they started out at dawn to hunt antelopes. With the first ray of sunlight that fell on the sand, they intended to 'kill' the antelope. Their first arrow hit the drawing unerringly in the neck. Then they went out to hunt and returned with a slain antelope. Their death-dealing arrow hit the animal in exactly the same spot where, hours before, the other arrow had hit the drawing ... $[H]$ aving fulfilled its magic purpose ... this arrow was then removed from the drawing with an accompanying ritual designed to ward off any evil consequences of the murder from the hunters. After that was done, the drawing itself was erased.

For the researcher, the aforementioned hunting scene depicts the knowledge of the unity of being, and action based on the realisation of unity as follows:

1. The three men and one woman symbolise the unity of being.

2. The picture of the antelope on sand represents the object or goal of intention, in which case the form is represented and connected to intention through the senses.

3. The first ray of the sunlight that falls on the sand is related to knowledge of realisation of unity of being, knowledge and action.

4. The shot arrow (or physical representation of projection of consciousness) hits the symbolic antelope at the neck as realisation that intention, energy and action have converged in the timeless and spaceless 'now'.

\section{The neutral dimension}

\section{Gathering}

\section{How is mankind gathering?}

The second dimension of the proposed model of consciousness in Figure 1 is characterised by the 'movement of the form' or 'gathering' based on the realisation and affirmation of the necessity for forgiveness and reconciliation, preceded by total dialogue. Gathering presupposes a 'Khotso' mentality.

\section{Khotso - The way of forgiveness and reconciliation preceded by total dialogue}

Among the Basotho, peace (Khotso) was and is still a cornerstone virtue (Matšela 1979). For the former, peace is a fundamental virtue that involves intrapersonal and interpersonal harmony, and its absence inevitably compromises the expression and experience of all other virtues, like justice, charity and prosperity. The transpersonal attitude of peace and reconciliation with 'all' categories of individuals is aptly demonstrated in the life of Moshoeshoe the Great, who acting on the advice of his mentor, chief Mohlomi, pacified the belligerent King Shaka and not only forgave but integrated cannibals who had eaten his grandfather (Casalis 1997).
Khotso is the essential dynamic in the philosophy of reconciliation through dialogue for self-transcendence and resistance of fragmentation. Self-transcendence through Khotso can be likened to 'the philosophy of dialogue', which is dialogical, intersubjective, arising within what Buber (1947) identifies as 'the between'. Self-transcendence occurs not from some neutral standpoint within an individual's rational act, but from the standpoint of relationship with the other. It appears as a form of knowledge that is intrinsically relational and, according to Ihde's typology, is auditory rather than visual (Ihde 2007), depending on listening and speaking, with a prerequisite of freedom of speech.

Khotso as peace through self-transcendence is logically an intersubjective, social act; cannot be achieved by isolated, fragmented individuals; and is fundamentally incompatible with neoliberal 'market forces conditioned culture'. Peace and reconciliation are reflective of what Johann (1966) calls 'disinterested love' or love as the essence of Being, which forms the core substance-energy of authentic dialogue for peace and reconciliation. 'Khotso love' is definitely not the 'interested' attachment of romantic love or neoliberalist desire for benefit.

\section{Gathering and Gebser's mythical structure}

With the mythical structure of consciousness, imagination becomes a distinctive component, and through language, man is able to communicate and construct reality, to become in a way the creator of his world (Feuerstein 1987). Humanity begins to relate all that is known of the world in stories, or myths. Gebser (1985) wrote that these myths their stories representing the internal experience of mankind and their ability to speak of them was their new power. He showed how the numerous stories of mankind being lost at sea and finding themselves on shore was representative of mankind's individual ego finding themself within, or apart from, the collective. Homer's Odyssey, Noah, and Gilgamesh are a few examples that illustrate mankind finding themselves after a flood or being lost at sea. There is a strong affinity for time within these stories, and the orientation of consciousness was one of looking back (Feuerstein 1987). For the researcher, the mythical structure of consciousness implies a 'transpersonal meaning-making of reality', which is at once mindful and thoughtful of the underlying unity, continuity and infinity of being, knowing and doing.

\section{The sustaining dimension \\ Tool-making}

\section{Why and for what is mankind making tools?}

The third or sustaining dimension of the proposed model of consciousness evolution through hunting, gathering, toolmaking and art presupposes the materialisation of forms representative of both 'intention of unity and movement of the form of unity'.

\section{Tool-making and the positive aspects of Gebser's mental structure}

Mankind's entrance into the mental structure is characterised by a tremendous leap in consciousness. Gebser (1985) used 
the myth of the birth of Athena to illustrate this shift. Athena, goddess of wisdom and intellect, tore out of the head of Zeus and brought forth the wakefulness and vision of mankind. Gradually, the gods become replaced with mankind's apprehension of their own thinking. While the mythical structure could be said to be related with speech and storytelling, the mental structure is defined by vision and space.

It was not that depth and space did not exist previously, but the birth of perspective brought something new to the human experience (Combs 2014). Through the awareness of location in relation to objects, a heightened sense of depth and spatiality became a new component of consciousness, and this new capacity allowed the world to be viewed in terms of objectivity. The realisation of being an internal creature in an external environment finalised the separation from nature, while mankind's ability to think in terms of perspective allowed them to rationalise and reason.

\section{The reinforcing dimension}

\section{Art}

\section{What is the goal of mankind's art?}

The fourth dimension of consciousness evolution or the reinforcing stage is the integration of intention or form of the movement of the form and movement of the form, into a form of the movement of the realisation of the unity, continuity and infinity of being, knowing and doing. Art on this basis is a 'representational and activating prism' through which consciousness both reflects and crystallises unity, continuity and infinity of being, knowing and doing, and at the same time and space dissolves separation, discontinuity and limitation of being, knowing and doing.

\section{Art and Gebser's integral structure}

Breaking free from the Newtonian Cartesian model of consciousness into a new dimension of reality requires more than just an expansion of consciousness, or an acceptance of new ideas. As Gebser (1985) stated, the expansion of consciousness is still just a quantitative and spatial conception, and an illusion. It is related to the material concept of consciousness, or consciousness as the accumulation of ideas. What is needed is the growth of consciousness, which is an intensification of it. This structure is a four-dimensional reality; its achievement is not an intellectual capacity, but rather results from the integration of all other structures. Gebser (1985) said integration comes about from the concretion, or condensation of the early structures, where all the positive and negative attributes have been resolved, rather than a mental apprehension of them. The role of perspective in the mental structure is contrasted to that of the aperspectival in the integral. This term refers to a transcendence of perspective. In comparison with the chronological orientation of time of the mental structure, this structure is free of temporal and spatial limitations; it is an egoless and a holistic view of reality (Roje 1994).

\section{Art - Hunting magic or crystallisation of infinity}

Henri Breuil (Straus 1992; 1994) interpreted Palaeolithic cave paintings of animals as being representative of hunting magic. In other words, the depicted hunting scenarios could have acted as 'consciousness prisms' for accelerating the convergence of intention, energy and outcome in time and space, as a unity of being, knowing and doing.

\section{Art - Mummification as crystallisation of unity and continuity}

Mummies of humans and other animals have been found on every continent both as a result of natural preservation through unusual conditions, and as cultural artefacts. A mummy is a deceased human or an animal whose skin and organs have been preserved by either intentional or accidental exposure to chemicals, extreme cold, very low humidity or lack of air, so that the recovered body does not decay further if kept in cool and dry conditions. For the researcher, the process of mummification is most likely representative of an attempt at trans-temporality or the transcendence of the disintegrative effects of time on substance. Mummification therefore implies the intention of crystallising 'continuity and infinity' of being.

\section{Dis-consciousness}

\section{Definition}

For the researcher, if there is consciousness, it is not impossible to have 'states of dis-consciousness'. Dis-consciousness for the researcher is perception, invocation, crystallisation of the nonintegral dis-continuity of non-being (separation, discontinuity and limitation of substance, energy, light and power), nonknowing (perception of the separation, discontinuity and limitation of substance, energy, light and power) and undoing (deformation, destruction and disintegration of non-integral, discontinuous, limited substance, energy, light and power). Dis-consciousness for the researcher can be termed 'perception', that is, sensing, invocation and experiencing 'only of separation, discontinuity and infinity' of non-being, nonknowing and undoing as defined. Furthermore, disconsciousness or 'sensing-perception' 'actively opposes' the realisation, affirmation and crystallisation of integral continuity of being, knowing and doing. Perception on the contrary crystallises experiences of separate, discontinuous and limited substance, energy, light and power.

In other words, 'dis-consciousness' never 'realises' unity, continuity and infinity of substance, energy, light and power, in which case the latter 'are deflected from its circumstantial existence'. Thirdly, dis-consciousness implies personalisation, or conditioning through the 'perception of dualities', through fundamental sensing of 'non-integral dis-continuity'. Fourthly, there cannot be evolution through 'the perception of dis-consciousness', only dis-evolution, 'regression'. Fifthly, dis-consciousness determines the 'direction-orientationeffect of the forms and outcomes' of hunting, gathering, toolmaking and art. The forms and quality of the outcomes of hunting, gathering, tool-making and art directed by disconsciousness have the following attributes: 
1. Crystallisation of separation, discontinuity and limitation of substance, energy, light and power.

2. Dissolution of unity, continuity and infinity of substance, energy, light and power.

3. Separation and antagonism of substance, energy, light and power.

4. Imprisonment and contraction of substance, energy, light and power.

5. Degeneration, destruction and disintegration of substance, energy, light and power.

\section{Gebser's mental structure and dis-consciousness}

Unlike the previous consciousness structures, consciousness mutation through mental development leads to a heightened sense of individuality and a capability of directing and discursive thought (Feuerstein 1987). However, the ability of mankind to rationalise has come with the cost of their disregard of and need to 'fragment' the world. Perspective gives dominion over space, but an ever- increasing need for dominion has created a separateness of mankind from the whole as found in relative degrees in the archaic, magical, mythical and integral structures of Gebser. Dis-consciousness easily leads to 'soulless', intelligent or unintelligent hunting, gathering, tool-making and art.

There is therefore the possibility of dissonance and even disconnectedness between the form of the movement, movement of the form and form of the movement of intelligence on the one hand and those of consciousness on the other. In other words, hunting, gathering, tool-making and art could demonstrate apparent 'evolution' of intelligence, but the ends, goals and objectives of the former could reflect the 'regressive movements of dis-consciousness'. The latter could be seen in outcomes of either the 'dissolution of unity, continuity and infinity' or 'crystallisation of separation, discontinuity, and limitation'.

\section{Horizontal evolution}

The idea of horizontal evolution of consciousness is suggested by the fact that over the course of human history there have arisen an increasing number of ways human beings have come to experience the cosmos. It was not until the publication of Descartes' Meditations on First Philosophy in 1641, however, that the distinction between an inner world of thought and feeling and an outer world of physical objects and objective reality was systematically defined. For this reason, Descartes is sometimes said to have 'invented' the modern notion of consciousness as an inner dimension of experience. With Descartes we can say that the world of human experience had become divided into two realms, or two perspectives, an inner perspective and an outer perspective, or a bifurcation in perspective, which created two worlds of experience out of one original world.

The development of what Gebser termed perspectival consciousness during the Renaissance, the perception of being in a particular location in space, made it possible for Descartes, in his Meditations, to adopt an 'objective' stance, even in his own mind, from which to view the realities of his inner life. Materialism appeared full-blown only after Descartes created the division of the cosmos into an inside, or 'consciousness' and an outside, or matter; the latter being made possible by the presence of perspectival consciousness. Descartes and subsequently Newton were absolute materialists where the physical world was concerned, through a prevalent philosophy of Logical Positivism, which claims that all scientific statements must be understood strictly in terms of objective observations.

\section{The enabling dimension of dis-consciousness \\ Hunting}

The enabling dimension of dis-consciousness could be summarised as the 'impulse to resist integration or reconciliation' which is exemplified in the neoliberalist ethos. The latter is the epitome of 'dissolution of unity, continuity, and infinity' by crystallising instead 'separation, discontinuity and limitation'.

\section{Neoliberalism, fragmentation and the resistance of integration}

Hunting through a neoliberalist prism aims for fragmentation and opposition to reintegration.

A consensus is emerging among some political theorists, economists, sociologists, geographers and theologians that the moral ideology and economic practices designated by the term neoliberalism represents the current reigning hegemony. Known to the general public as simply 'the free market', the three-fold economic agenda of neoliberalism is free trade in goods and services, free circulation of capital and freedom of investment (George 2000). It accomplishes this agenda through a trinity of instruments: deregulation, globalisation and technological revolution (Bello et al. 2000). Socio-economic consequences include the privatisation of public wealth, suppression of fair wages, record poverty and a global increase in economic inequality. Psychologically, neoliberalism yields what amounts to a new type of human being, distinguished by the fragmentation, discontinuity and fluidity of the self (Dufour 2001; 2008; Harvey 2005; Rogers-Vaughn 2012). This is associated with a global increase in the full range of what has come to be called mental illness: self-disorders, narcissism, depression, anxiety, addictions, etc., as well as the disruption of human attachment and relationships at every level (Alexander 2008; Bauman 2003; Dufour 2001; Wilkinson \& Pickett 2009).

\section{The neutral dimension of dis-consciousness}

\section{Gathering}

The neutral dimension of dis-consciousness or 'gathering' is characterised by hostility, overt antagonism and violence of 'fragmented human communities and idiosyncrasies'. The movement of the form of dis-consciousness is rooted in a bedrock of 'persistent and festering ill will'.

\section{Sectarianism, exclusivism and intolerance}

The question can be asked of how mankind is 'gathering nowadays'. It would seem there is a prevalence of 
sectarianism, exclusivism, radicalism, fundamentalism and marked intolerance. Instances which justify the preceding presupposition are legion, but the most prominent among them are xenophobia, genocide, ethnic cleansing, the Holocaust and intrareligious and interreligious violence.

\section{The sustaining dimension of dis-consciousness Tool-making}

The sustaining dimension of dis-consciousness or 'toolmaking' represents the self and all destructive ends to which weapons of mass disintegration are being put to abuse and disservice of mankind and the environment. This dimension is characterised by the 'release of infernal implosive-explosive impulses' whose sole 'pseudo-ecstasy' is mass annihilation, in a kind of 'demonisation of will'.

\section{Arms race and terrestrial annihilation}

The arms race is like a 'mass frenzy' towards dissolution of unity, continuity and infinity of self and others, through the instruments of technology which have as goals 'implosiveexplosiveness' of structures and forms. There is the rise of suicidal tendencies as seen in suicide bombers or 'modern day kamikaze pilots', toying with nuclear tests, untold savagery in festering regional wars, global warming and cooling through criminal pollution, etc.

\section{The reinforcing dimension of dis-consciousness}

\section{Art}

The reinforcing dimension of dis-consciousness is labelled 'art', which in this perspective represents forms of the movement which aim at dissolving both unity, continuity, infinity, separation, discontinuity and limitation. Pseudo-art of the reinforcing dimension is a veritable 'solvent of consciousness' through the regressive return to 'pre-consciousness archaic state' of non-individualisation and non-personalisation.

\section{Conclusion}

For the researcher, hunting, gathering, tool-making and art are prisms or forms of the intelligent movement of consciousness or the intelligent movement of dis-consciousness, founded either on the intention of 'inseparable or irreconcilable dualities'. Hunting, gathering, tool-making and art are expressions and experiences of 'forms of evolution of intelligence', in dissonance or consonance, respectively, with movements of 'irreconcilable dualities or inseparable dualities of dis-consciousness or consciousness'. In other words, hunting, gathering, tool-making and art are reflective of forms of development of intelligence, which could be reflective or not of consciousness (realisation of unity of being) or of disconsciousness (perception of separation of being). Hunting, gathering, tool-making and art are subsequently four prisms through which either consciousness evolves or through which dis-consciousness is reflected.

Are all human expressions and experiences not either forms of the movement, movements of the form, forms of the movement of the form of dis-consciousness or forms of the movement, movements of the form and forms of the movement of the form of consciousness? Are hunting, gathering, tool-making and art not perennial human activities that demonstrate either the convergence or dissonance of the evolution of intelligence and consciousness, in which the former depicts states of 'authentic civilisation', whereas the latter makes of mankind 'enlightened barbarians'?

If intelligence evolves in separation from the development or underdevelopment of consciousness, will the mind and senses not become the 'tools' of dis-consciousness? In other words, is the degree of expansion and enlightenment of the senses and intellect not related to the quality of consciousness development? If hunting, gathering, toolmaking and art are at the service of conscious intelligence, will mankind's destiny not be one of infinite, positive, self and all transformation?

For the researcher, the main issue in consciousness evolution is not the mechanical mastery of energy, at different progressively elevated levels, but the source of the control and the orientation of harnessed energy of 'hunting, gathering, tool-making, and art'. In other words, is it 'consciousness force' which harnesses, controls and distributes nuclear, natural, plant, animal and physical energies, or are the latter harnessed and controlled by purely dis-conscious mechanical, intellectual, military and market forces? If the former is the case, then we can expect hunting, gathering tool-making and art to be at the service of mankind and the environment, whereas if the latter scenario predominates, then 'the potential for senseless self and all destruction' is inevitable. In the same light, the researcher asks the following question: is it true that technological progress is the fundamental factor which drives the development of mankind's civilisation? How then can we reconcile the extreme levels of violence and extinction of defenceless species by members of 'civilised humanity'? Are the so-called 'civilised' not the real barbarians, given their misguided technological advantage over 'voiceless and harmless others'?

\section{Acknowledgements Competing interests}

The author declares that he has no financial or personal relationships which may have inappropriately influenced him in writing this article.

\section{References}

Alexander, B.K., 2008, The globalization of addiction: A study in poverty of the spirit, Oxford University Press, New York.

Bauman, Z., 2003, Liquid love: On the frailty of human bonds, Polity Press, Cambridge, UK.

Bello, W., Malhotra, K., Bullard, N. \& Mezzera, M., 2000, 'Notes on the ascendancy and regulation of speculative capital', in W. Bello, N. Bullard \& K. Malhotra (eds.), Global finance: New thinking on regulating speculative capital markets, pp. 1-26, Zed Books, New York.

Buber, M., 1947, Between man and man, Kegan Paul, London. 
Casalis, E., 1997, The Basutos Morija Museum \& archives (1861 edition), Morija Printing Works, Moriija, Lesotho.

Combs, A., 2014, 'Art and the evolution of consciousness', Eros and Kromos, viewed 22 April 2016, from http://eroskosmos.org/english/art-and-evolution-of-consciousness/ Dictionary.com

Dufour, D.R., 2001, The individual in disarray. Le Monde diplomatique, viewed 22 April 2016, from http://mondediplo.com/2001/02/09mansestate

Dufour, D.R., 2008, The art of shrinking heads: On the new servitude of the liberated in the age of total capitalism, transl. D. Macey, Polity Press, Cambridge, UK.

Feuerstein, G., 1987, Structures of consciousness: The genius of Jean Gebser: An introduction and critique, Early Printing edn., Integral Publishing, Lower Lake, CA.

Gebser, J., 1985, The ever-present origin, authorized translation by Noel Barstad with Algis Mickunas, Ohio University Press, Athens.

George, P., 2007, The white bedouin, Council Press, Cedar Fort, Incorporated/CFI Distribution, Springville.

George, S., 2000, 'A short history of neoliberalism: Twenty years of elite economics and emerging opportunities for structural change', in W. Bello, N. Bullard \& K. Malhotra (eds.), Global finance: New thinking on regulating speculative capital markets, pp. 27-35, Zed Books, New York.

Harvey, D., 2005, A Brief History of Neoliberalism, Oxford University Press, Oxford.

Ihde, D., 2007, Listening and voice: Phenomenologies of sound, State University of New York Press, Albany, NY.
Johann, R.O., 1966, The meaning of love: An essay towards a metaphysics of intersubjectivity, Paulist Press, Glen Rock, NJ.

Leo, L., 1933, Kulturgeschichte Afrikas, Phaidon, Vienna.

Matšela, F.Z.A., 1979, 'The indigenous education of the Basotho and its implications for educational development in Lesotho', Unpublished Thesis, University of Massachusetts.

Mohrhoff, U.J., 2008, 'Evolution of consciousness according to Jean Gebser', Ant Matters 2(3), 51-78, viewed 7 October 2014, from http://anti-matters.org/ articles/74/public/74-67-1-PB.pdf

Rogers-Vaughn, B., 2012, 'The social trifecta of human misery and problematical constructions of the self: Implications for formation and supervision', Reflective Practice: Formation and Supervision in Ministry 32, 206-223.

Roje, J., 1994, 'Consciousness as manifested in art: A journey from the concrete to the meaningful', The Arts in Psychotherapy 21(5), 375-385. https://doi. org/10.1016/0197-4556(94)90065-5

Straus, L.G., 1992, 'L'Abbé Henri Breuil: Archaeologist', Bulletin of the History of Archaeology 2(2), 5-9. https://doi.org/10.5334/bha.02102

Straus, L.G., 1994, 'L'Abbé Henri Breuil: Pope of Paleolithic Prehistory', in Homenaje al Dr. Joaquín González Echegaray, pp. 189-198, Museo y Centro de Investigación de Altamira, Madrid.

Wilkinson, R. \& Pickett, K., 2009, The spirit level: Why greater equality makes societies stronger, Bloomsbury Press, New York. 